Illinois State University

ISU ReD: Research and eData

Theses and Dissertations

$5-28-2020$

\title{
Low In Advantageous Personality Traits? Find An Alternative Path To Higher Job Performance
}

Ares Boira Lopez

Illinois State University, aresboiralopez9@gmail.com

Follow this and additional works at: https://ir.library.illinoisstate.edu/etd

Part of the Organizational Behavior and Theory Commons

\section{Recommended Citation}

Boira Lopez, Ares, "Low In Advantageous Personality Traits? Find An Alternative Path To Higher Job Performance" (2020). Theses and Dissertations. 1270.

https://ir.library.illinoisstate.edu/etd/1270

This Thesis is brought to you for free and open access by ISU ReD: Research and eData. It has been accepted for inclusion in Theses and Dissertations by an authorized administrator of ISU ReD: Research and eData. For more information, please contact ISUReD@ilstu.edu. 


\title{
LOW IN ADVANTAGEOUS PERSONALITY TRAITS? FIND AN ALTERNATIVE PATH \\ TO HIGHER JOB PERFORMANCE
}

\begin{abstract}
ARES BOIRA LOPEZ
42 Pages

Extensive research has provided evidence that the trait positive affect (PA) and the personality trait conscientiousness are positively related to job performance (JP). Although recent studies have challenged the common perspective that these traits do not change, their variability is often low. Thus, their stability makes these traits especially useful for hiring practices. However, for developmental purposes, that same characteristic might pose limitations to effective increases in employees' performance. The current study aims to offer a solution to contribute to the research and practice of employee development. Given the potential difficulty of changing an individual's PA, this article develops hypotheses based on the idea that by gaining knowledge on trainable processes that mediate the relationship between PA and JP, employers can focus on those processes to increase the performance of current employees with low PA. With a sample of 131 Air Force officer candidates along the course of 2 years, general self-efficacy (GSE) and social self-efficacy (SSE) will be examined as mediators of the relationship between PA and JP. Moreover, the sixth and seventh hypotheses of the current study intend to find evidence that GSE and SSE is more predictive of JP for individuals low in conscientiousness than those higher. Thus, conscientiousness will be tested as a moderator in the relationship between GSE and JP, and SSE and JP. The findings emphasize the need for further
\end{abstract}


research on SSE as this study has shown that it is a strong indicator of performance and that its development can drive individuals with low positive affect to higher performance.

KEYWORDS: Positive Affect; General Self-efficacy; Social Self-efficacy; Conscientiousness;

Job Performance 
LOW IN ADVANTAGEOUS PERSONALITY TRAITS? FIND AN ALTERNATIVE PATH

TO HIGHER JOB PERFORMANCE

ARES BOIRA LOPEZ

A Thesis Submitted in Partial

Fulfillment of the Requirements

for the Degree of

MASTER OF SCIENCE

Department of Psychology

ILLINOIS STATE UNIVERSITY

2020 
(C) 2020 Ares Boira Lopez 
LOW IN ADVANTAGEOUS PERSONALITY TRAITS? FIND AN ALTERNATIVE PATH

TO HIGHER JOB PERFORMANCE

ARES BOIRA LOPEZ

COMMITTEE MEMBERS:

Eric Wesselmann, Co-chair

Alex Barelka, Co-chair

Scott Jordan 


\section{CONTENTS}

Page

TABLES

iii

FIGURES

iv

CHAPTER I: LITERATURE REVIEW

Trait Positive Affect

Trait Stability

$\begin{array}{ll}\text { Self-efficacy (GSE \& SSE) } & 7\end{array}$

Self-efficacy and Trait Positive Affect $\quad 8$

Self-efficacy and Job Performance $\quad 9$

$\begin{array}{ll}\text { Increasing Self-efficacy } & 10\end{array}$

$\begin{array}{ll}\text { Conscientiousness } & 11\end{array}$

$\begin{array}{ll}\text { Trait Stability } & 12\end{array}$

$\begin{array}{ll}\text { Self-efficacy and Conscientiousness } & 12\end{array}$

CHAPTER II: RESEARCH DESIGN 16

$\begin{array}{ll}\text { Method } & 16\end{array}$

$\begin{array}{ll}\text { Sample } & 16\end{array}$

$\begin{array}{ll}\text { Procedure } & 16\end{array}$

$\begin{array}{ll}\text { Measures } & 16\end{array}$

CHAPTER III: RESULTS 19

CHAPTER IV: DISCUSSION 23

Traits and Job Performance $\quad 23$

Self-efficacy as a Mediator of the Positive Affect-Job Performance Relation 25 
Conscientiousness as a Moderator of the Self-efficacy-Job Performance Relation

Implications of Self-efficacy in the Workplace

Implications of Self-efficacy in Research

Limitations and Further Research

Conclusion

REFERENCES 


\section{TABLES}

$\begin{array}{lll}\text { Tables } & \text { Page }\end{array}$

1. Correlations, Means, and Standard Deviations among Traits, Self-efficacy, and Job

Performance 


\section{FIGURES}

Figures $\quad$ Page

1. The hypothesized relations between positive affect, general self-efficacy, social selfefficacy, conscientiousness, and job performance

2. Standardized regression coefficients for the relation between positive affect and job performance as mediated by general self-efficacy

3. Standardized regression coefficients for the relation between positive affect and job performance as mediated by social self-efficacy

4. Simple slopes of social self-efficacy predicting job performance for $1 \mathrm{SD}$ below the mean of conscientiousness, the mean of conscientiousness, and 1 SD above the mean of conscientiousness 


\section{CHAPTER I: LITERATURE REVIEW}

A hundred years ago, Frederick Winslow Taylor (1911) attempted to increase employee performance by developing a business system that focused on the "one right way to do a task", and motivated workers with economic incentives. One of the critiques that he received was that the system worked under the assumption that employees operate like "machines", and their emotions and individual characteristics were never considered (Ralston, 2014). This notion led to the publication of books like Job Satisfaction by Robert Hoppock (1935), who emphasized that employee's happiness leads to higher levels of productivity. At first, job satisfaction was considered a good indicator of happiness, so multiple studies examined its relationship with job performance, often finding contradictory results (Brayfield \& Crockett, 1955; Laffaldano \& Muchinsky, 1985; Thoresen, Bonno, \& Patton, 2001). Researchers noticed that past studies on job satisfaction had focused on judgment based, cognitive evaluations and generally ignored affective antecedents of evaluations of jobs (Judge, Hulin, \& Dalal, 2009). Thus, the construct of affect emerged to assess emotions in the workplace (Watson \& Clark, 1984). Moreover, Diener, Sandvick, Colvin, and Pavot (1991) found that affect, the relative proportion of time that people feel positive relative to negative emotions is a good indicator of self-reports of happiness.

Since then, many studies have provided support of the connection between trait positive affect, described as the stable tendency to experience positive emotions (Watson \& Clark, 1984), and job performance (Staw \& Barsade, 1993; Romero et al., 2017). Among other individual characteristics, the field of I-O psychology has also been interested in the impact of the personality trait conscientiousness on job performance (Hurtz \& Donovan, 2000). Findings indicate that conscientiousness, the trait associated with being organized, methodic, and thorough (Goldberg, 1993), is the strongest predictor of job performance after general mental ability 
(Hurtz \& Donovan, 2000). This all suggests that trait positive affect and conscientiousness are positively related to job performance.

The issue is that the literature has found contradictory findings on the variability of both traits affect and conscientiousness across the life course (Rantanen, Metsapelto, Feldt, Pulkkinen \& Kokko, 2007; Roberts \& Viechtbauer, 2006; Specht, Egloff \& Schmukle, 2011; Watson \& Walker, 1996). Although recent findings have challenged the common perspective that personality traits do not change, the variability found in the trait conscientiousness was rather small (Roberts \& Viechtbauer, 2006). In the case of trait positive affect, several studies have shown that it is possible to induce state positive affect (temporal emotions) (Baron, 1990), but trait positive affect (longer-lasting emotional dispositions) is moderately stable across a lifetime (Watson \& Walker, 1996). Therefore, the use of these stable and immutable traits might be more adequate for selection purposes but limiting for employee development. The current study proposes a potential solution for such a constraint and contributes to the research and practice of employee development.

The focus of this study will be to examine a new mediator of the relationship between trait positive affect and job performance, that offers employee developmental opportunities, and that is especially predictive of job performance for those employees low in conscientiousness. To accomplish this objective, the mediating effects of general self-efficacy and social self-efficacy in the PA-JP relationship will be examined, as well as the moderating effects of conscientiousness on the relation between general Self-Efficacy and job performance. If both types of self-efficacy explain some of the causal sequence between trait positive affect and job performance, managers may decide to focus on developing employee general and social selfefficacy, given the difficulty of increasing the employee trait positive affect. The same 
implication is offered for employees low in conscientiousness, whose personality might be more difficult to change, but whose increase in general self-efficacy may offer an alternative path to higher performance.

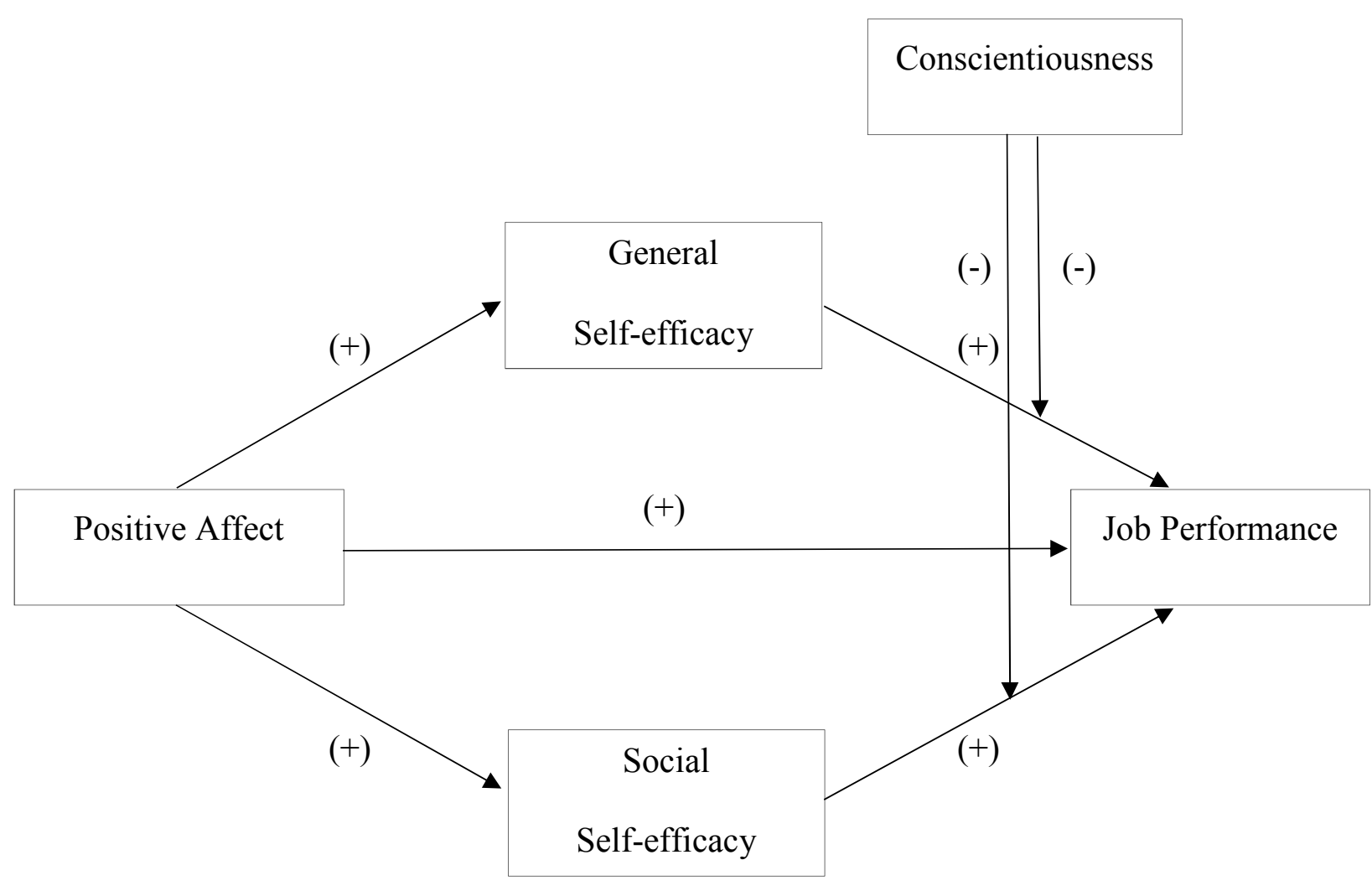

Figure 1. The hypothesized relations between positive affect, general self-efficacy, social selfefficacy, conscientiousness, and job performance.

Although there have been studies that claimed to have found positive affect and selfefficacy predictive of job performance, one of the common limitations was that their validation was concurrent (PA, SE and JP gathered in the same time frame) (Barsade \& Staw, 1993, Schunk, 1990). For example, this was the case for Barsade and Staw's (1993) article looking at affect and managerial performance, in which analyses were associative rather than causal. In other instances, studies claiming a causal effect of positive affect and productivity, used state 
affect as the predictor instead of trait affect, which was induced during the experiment and measured at the same time as performance (Isen \& Means, 1983). In research on self-efficacy, Schunk (1990) presented some studies that had for example, measured task achievement and self-efficacy at the same point in time, not allowing for valid predictive inferences. A few exceptions are found, however, that provide some evidence for predictive validity. Abele and Spurk (2008) examined the impact of occupational self-efficacy on career attainments. Using a sample of 734 full-time employees, they found that self-efficacy measured at career entry had a positive impact on salary change and career success after 7 years. They examined occupational self-efficacy, which is one's belief in their ability to perform at work.

However, the present study uses different measures of self-efficacy: general self-efficacy, which is not tied to any specific job or task, and social self-efficacy, which is one's belief in their ability to engage in social interactional tasks necessary to initiate and maintain interpersonal relationships (Sherer et al., 1982). The independence that these two measures of self-efficacy have with specific tasks that vary job to job, increases the generalizability and the external validity of the present findings. Also, although existent, longitudinal studies that support the statement that trait positive affect and self-efficacy predict job performance are rare. This suggests that there is a need to further confirm the relationship between positive affect, selfefficacy, and job performance beyond this small subset of studies. The present study used measures to assess PA, GSE and SSE at one point in time, and then measured job performance 18-22 month later. Given the need for more predictive validity, the first hypotheses will contribute to the literature by using longitudinal data to infer predictive validity of both relations.

H1: Trait positive affect will predict higher job performance.

H2: General self-efficacy will predict higher job performance. 
H3: Social self-efficacy will predict job performance.

\section{Trait Positive Affect}

Researchers in Industrial-Organizational psychology have been long intrigued by whether "happy" workers are "better" workers (Brayfield \& Crockett, 1955; Laffaldano \& Muchinsky, 1985; Kaplan, Luchman, \& Bradley-Geist, 2009). In the 1980s, happiness in the workplace was reconceptualized in terms of affect (Watson \& Clark, 1984; Diener, Sandvik, Colvin, \& Pavot, 1991). Therefore, most studies that focused on the impact of happiness on employee success used affect as their predictor measure. Specifically, they examined trait positive affect, the stable tendency to experience positive emotions such as enthusiasm and alertness (Watson \& Clark, 1984). The distinction must be made between state affect, which includes moods and fleeing emotions, and trait affect, which is more stable and considered a personality characteristic. Several studies have found that trait positive affect is related to attitudes and behaviors that increase performance (Staw \& Barsade, 1993; Romero et al., 2017).

\section{Trait Stability}

Although its predictive power has raised its importance in the field of talent management, trait positive affect may be most useful for hiring practices but limiting for employee development. Watson and Walker (1996) examined the long-term stability of their participants' trait positive affect during a 7-year period. Although trait negative affect declined significantly, trait positive affect showed a moderate level of stability. Moreover, the participants were initially assessed as undergraduates, which the authors suggest might have led to underestimating the trait stability for the rest of the population. A more recent study that looked at the stability of the Big Five personality traits and affective traits among young adults found some significant changes across the three tests the participants took throughout a 3-year period (Vaidya, Gray, Haig, 
Mroczek, \& Watson, 2008). Trait positive affect showed modest but inconsistent increases across both retests. Thus, the patterns of change on PA were found to be rather small and inconsistent across individuals. The authors noted that even if their findings revealed some better understanding of how personality changes during young adulthood, little is known about what causes these changes. Therefore, regardless of the weight that PA has on job performance, trying to increase employees' trait positive affect might not be the most effective path towards reaching higher performance.

On the other hand, identifying processes through which trait positive affect increases job performance may provide new opportunities to improve the latter. The reasoning behind that suggestion is that if processes behind the casual sequence between PA and JP are trainable, employers can increase low PA employees' performance by developing these processes directly instead. Multiple studies have already brought to light some of these processes either through conceptual or empirical mediation models (Ashby, Isen \& Turken, 1999; Isen \& Means, 1983; Knippenberg, Wisse, van Kleef \& Damen, 2008; Isen \& Reeve, 2005; Seo, Feldman \& Bartunek, 2004). Ashby, Isen and Turken (1999) found that PA changed dopamine levels which in turn improved performance in a variety of cognitive tasks. Unfortunately, that information is of little use for employee developmental purposes. Other studies, however, like Isen and Means' (1983) revealed that PA increased job performance by improving the decision-making process. It has been estimated that major decisions in firms have a failure rate higher than 50\% (Nutt, 2002). Employers can improve employees' decision-making skills by promoting strategies such as the ones suggested by Reeshad and Bolunmez (2016). Seo, Feldman and Bartunek (2004) found that individuals with high PA were more likely to set higher goals and persist during goal pursuit, two behaviors that are acknowledged to be crucial for successful performance. Companies may 
benefit from these findings by encouraging employees to set challenging goals and by instigating persistence, for example, by interspersing easier, more achievable goals among more challenging ones (Martin \& Pear, 2019). Given the usefulness of knowing the processes that explain the relation between PA and JP, the present article intends to contribute to the literature by examining self-efficacy as a new mediator.

\section{Self-efficacy (GSE \& SSE)}

Self-efficacy is described as the beliefs in one's capabilities to mobilize the motivation, cognitive resources, and actions needed to meet given situational demands (Wood \& Bandura, 1899). Although sometimes used interchangeably with other similar constructs, like self-esteem and self-confidence, it is important to make the distinction. Even though all these constructs refer to beliefs of one's abilities to thrive, self-efficacy is specific to tasks. Given that self-efficacy refers to one's confidence to be successful at a task, many researchers have created self-efficacy measures for specific situations, like academic self-efficacy or occupational self-efficacy (Schunk, 2002). For the purpose of this study, two subscales of self-efficacy will be examined: general self-efficacy, referring to the belief in one's competence to tackle novel tasks and to cope with adversity in a broad range of stressful or challenging encounters (Luszcynska, Gutierrez \& Schwarzer, 2009); and social self-efficacy, described as one's belief in their ability to engage in social interactional tasks necessary to initiate and maintain interpersonal relationships (Sherer et al., 1982). These constructs have been considered an important motivational component because they influence behavioral choices and effort expenditure (Klein, 1989). Numerous studies found that higher levels of self-efficacy led to the pursuit of higher-level goals, greater commitment, and a better interpretation of feedback (Locke \& Latham, 1990; Silver, Mitchell, \& Gist, 1991). 
This self-evaluation process has been associated with trait positive affect and job performance in the past, making it a potential mediator between the two.

\section{Self-efficacy and Trait Positive Affect}

There is theoretical and empirical evidence that suggest that trait positive affect is positively related to general self-efficacy (Luszcynska, Gutierrez and Schwarzer, 2009). No research has been found that relates positive affect to social self-efficacy, but the following arguments will help build the theory behind the examination of such relationship. First, the most reliable source of self-efficacy is Enactive Mastery Experience, which consists of building confidence with previous successes and weakening it with previous failure (Bandura, 1994). However, our mind is often not objective and tends to remember information that is consistent with the mood (Forgas \& Bower, 1987). As an example, provided in a previous study, a musician who chooses to remember the negative or failed performances over positive or successful ones will likely underestimate performance capabilities (Hendricks, 2015). Indeed, Forgas and Bower (1987) tested these effects and found that happy subjects formed more favorable impressions and made more positive judgements than did sad subjects. Therefore, individuals high in positive affect are likely to remember more positive over negative experiences, which can increase both general and social self-efficacy levels.

High positive affect also enhances the impact of internal and external feedback on one's positive beliefs regarding their ability to perform (Kampkuiper, 2015). Some might think that in that case, it is only the feedback that causes higher self-efficacy due to social persuasion. However, theorists behind the mood congruency effect argue that individuals with high positive affectivity can create positive self-judgements from positive feedback, whereas individuals with low positive affectivity are unlikely to do so, due to the incongruency between the external 
positive treatment and the internal negative emotions about their own performance. Positive affect may explain some variance of general and social self-efficacy above and beyond performance feedback alone (Seo \& Illies, 2009).

Lastly, positive affect may increase general and social self-efficacy by favorably modifying the perception of the environment. Individuals with high levels of positive affect are likely to adopt a promotion focus approach, from which they perceive their experiences as opportunities for growth (Seo et al., 2004). Bandura's (1977) found that regulatory focus choice has an impact on perception of emotional arousal. Those who adopt a prevention focus, perceive it as stressful and taxing, as opposed to individuals who adopt a promotion focus, remain calmer and positively excited. Drawing from the fourth source of self-efficacy (Bandura, 1994), individuals who perceive their arousal as an energizing facilitator of performance have higher levels of self-efficacy, while those who perceive the arousal as stressful and weakening, display lower levels of self-efficacy. Therefore, people with high positive affect, who adopt a promotion focus, are likely to have higher levels of general and social self-efficacy.

\section{Self-efficacy and Job Performance}

Social-cognitive theorists argue that self-efficacy causes higher performance because it enables the effective regulation of behavior through a variety of cognitive, motivational, and affective decision-making processes (Bandura, 1997). Multiple studies support the positive relation between self-efficacy and work, academic, and interpersonal performance (Abele \& Spurk, 2009; Chemers, 2001; Stajkovic \& Luthans, 1998). As early as the 1980s, Bandura provided evidence that individuals with high self-efficacy beliefs set higher goals for themselves, put in more effort, and persisted longer on difficult tasks. According to goal-setting theory, individuals who set specific, difficult goals perform better than those who set general, easy goals 
(Locke \& Latham, 2006). Consequently, general self-efficacy and social self-efficacy should increase goal level in technical and interpersonal skills respectively, which should increase job performance (Schunk, 1990).

Besides having an impact on the goals that individual set, increasing self-efficacy also results in a greater resource investment while pursuing these goals, which leads to higher performance (Beck \& Schmidt, 2012). Employees with higher self-efficacy believe that they have the capabilities to accomplish the goals. Thus, they will most likely put the effort in pursuing them because they expect that more work will equal better results. Workers with low self-efficacy may tend to blame external factors and lose persistence due to the belief that they might not be good enough for a job or worthy of relationships with others and that it is unchangeable. Although some researchers have argued that if levels of self-efficacy are too high, over-confidence may lead to reduced effort (Vancouver, Thompson, Tischner, \& Putka, 2002; Yeo \& Neal, 2006), Beck and Schmidt (2012) showed that if the task is challenging, their findings do not hold true. Hence, employees with high levels of self-efficacy, who generally set challenging goals, are most likely to allocate resources in their pursuit of successful work and relationships, accomplishing greater overall performance.

\section{Increasing Self-efficacy}

It is not only evidence of its relationship with trait positive affect and job performance that makes self-efficacy an interesting construct to explore. Organizational studies have reported positive posttest differences in mean self-efficacy and job performance for participants who were exposed to various forms of self-management and modeling training (Frayne \& Latham, 1987; Gist, 1989; Gist et al., 1989), indicating that self-efficacy may be a malleable process. Further, Gist and Mitchell (1992) offered several intervention strategies to change employee self-efficacy. 
First, they advised employers to provide information that gives the employee a thorough understanding of the task attributes, complexity, task environment, and the way in which these factors can be best controlled. Second, they suggested companies provide training that directly improves the individual's abilities or understanding of how to use abilities successfully in performing the task. Third, they recommended managers to provide information that improves the employees' understanding of the effort expenditure required for task performance. The authors specified that these informational sessions and training should be provided primarily through the use of mastery, modeling, feedback, and persuasion experiences which correspond to the four main sources of self-efficacy developed below (Bandura, 1994).

H4: General self-efficacy will have a mediating effect on the effect of positive affect on job performance.

H5: Social self-efficacy will have a mediating effect on the effect of positive affect on job performance.

\section{Conscientiousness}

Conscientiousness is one of the big five traits of personality along with extraversion, agreeableness, emotional stability, and openness (Goldberg, 1993). It is a multifaceted construct that includes multiple domains. Firstly, orderliness, described as the overarching tendency to be "prepared". Secondly, industriousness, refers to the tendencies to work hard, aspire to excellence, and persist in the face of challenge. Third, self-control, the propensity to control impulses. Fourth, responsibility, defined as the tendency to follow through with promises to others and follow rules (Roberts, Lejuez, Krueger, Richards, \& Hill, 2012). Barrick and Mount's (1999) meta-analysis found support for the hypothesis that conscientiousness has a positive relation with all job performance criteria (job proficiency, training proficiency, and personnel 
data), for all occupational groups examined (professionals, police, managers, sales, and skilled/semi-skilled). Of all the personality traits in the Big Five framework, conscientiousness has been consistently found to have the highest validity for overall job performance (Hurtz \& Donovan, 2000).

\section{Trait Stability}

Findings on the stability of the personality trait conscientiousness show some controversy. A meta-analysis of longitudinal studies by Roberts and Viechtbauer (2006) revealed an increase in conscientiousness from age 20 to $30(d=.22, p=.05), 30$ to $40(d=.26, p=.05)$, and 40 to $50(d=.10, p=.05)$. However, even the authors recognized that an argument could be made that the changes were small in magnitude. A year after the publication of the metaanalysis, Rantanen, Metsapelto, Feldt, Pulkkinen and Kokko (2007) investigated the stability of the Big Five personality traits in adulthood from age 32 to 42 . They found that although trait conscientiousness increased across the 9 years, its stability was moderate to high. Their analyses showed that average personality changes were relatively small. Given the possibility that some individuals might have increased in a particular trait dimension, while others might have decreased, producing offsetting changes, they examined consistency at the intra-individual level. They found that when women experience employment related shocks, and men experience health, or family related shocks, they become slightly less conscientious overtime. Although their findings appear interesting for predictive purposes, its usefulness to train employees to become more conscientious is null.

\section{Self-efficacy and Conscientiousness}

This article advocates for the development of employee general and social self-efficacy as an alternative path to high performance. The literature suggests that some of the processes 
through which general, social self-efficacy and conscientiousness lead to job performance may overlap. For example, conscientiousness and both subscales of self-efficacy have been examined as an important determinant of goal-setting behavior (Barrick, Mount, \& Strauss, 1993; Bandura, 1997). The choice to expend effort, the choice of level of effort to expend, and the choice to persist in that level of effort are three choice behaviors that determine an individual's motivation and they are closely associated with traits that represent conscientiousness (Campbell et al., 2000). Barrick, Mount and Strauss (1993) explained that individuals who are high in conscientiousness are planful, organized, and purposeful, which leads to setting goals. Also, conscientious people are achievement-oriented, hardworking, and have high expectations of themselves, which leads them to setting more difficult goals. Similarly, individuals high in selfefficacy tend to set challenging goals and commit to their pursuit given their adoption of a promotion focus (Bandura, 1997). It is acknowledged that setting challenging goals leads to higher job performance (e.g., Shah \& Higgins 1997).

General self-efficacy and conscientiousness increase self-control which cause higher productivity (Barrick, Mount, \& Strauss, 1993; Bandura 1977). Given conscientiousness' association with the lateral prefrontal cortex, which is mostly implicated in a form of behavioral control, increased conscientiousness causes more frequent restrain of impulses that are disruptive of rules and plans involved in pursuing high performance (Vohs \& Baumeister, 2016). Furthermore, using exploratory and confirmatory factor analysis of multiple items, MacCann, Duckworth, and Roberts (2009) uncovered eights facets strongly related to conscientiousness, and being in control was one of them. Interestingly, the literature indicates that higher general self-efficacy beliefs also increase self-control on difficult tasks given self-efficacious 
individuals' faith in their capabilities to succeed that keeps them on task regardless of distracting stimuli, leading to accomplishments of greater job performance (Bandura, 1977).

Social self-efficacy and conscientiousness enhance interpersonal skills which leads to higher contextual performance in the workplace (Van Scotter \& Motowidlo, 1996). A facet embedded in conscientiousness is responsibility, which involves following through with promises to others (Roberts, Lejuez, Krueger, Richards, \& Hill, 2012). Further, studies like Campbell and Malcolm's (2007) have provided evidence that conscientiousness contributes to interpersonal relationships by revealing that adolescents higher on conscientiousness experienced less victimization, better quality friendships, and higher peer acceptance even after controlling for other big five dimensions. Similarly, findings by researchers like Connolly (1989) and Matsushima and Kunio (2003), indicate that social self-efficacy is a component of social competence, and negatively correlates with interpersonal stress.

Interestingly, related to effort and perseverance, Sun, Chen and Song (2016) found that individuals with higher levels of conscientiousness responded to lower self-efficacy with increased effort, resulting in an inverse relationship between self-efficacy and effort expenditure. In their study, they found moderating effects of conscientiousness in the relation between selfefficacy and effort allocation. Because effort allocation impacts job performance, the findings suggest that conscientiousness might likely be a moderator on the relationship between selfefficacy and job performance. However, the present study is particularly interested in whether general and social self-efficacy are more predictive of job performance for individuals with low levels of conscientiousness. Significant findings would support the argument that training general and social self-efficacy may not only be an alternative path to job performance for those 
low in positive affect but also for current employees who are not high in conscientiousness, as well.

H6: conscientiousness will have a moderating effect on the relationship between general self-efficacy and job performance, so that general self-efficacy will be more predictive of job performance for those employees with low conscientiousness.

H7: conscientiousness will have a moderating effect on the relationship between social self-efficacy and job performance, so that social self-efficacy will be more predictive of job performance for those employees with low conscientiousness. 


\section{CHAPTER II: RESEARCH DESIGN}

\section{Method}

\section{Sample}

The sample consisted of 131 individuals who were officer candidates for a commission in the Air Force. The average age of these individuals was $27.82(\mathrm{SD}=$ check!). They went through a twelve-week Officer Training School (OTS) program between 1994 and 1997. The training program was designed to train new military recruits between the ages of 21 and 35 to be officers in the United states Air Force. Candidates who successfully completed the training were commissioned as officers.

\section{Procedure}

During the first week of training, the participants completed surveys that included measures of positive affect, general and social self-efficacy, and conscientiousness. Between one and two years after the candidates had graduated from OTS, their supervisors were asked to rate the graduates' job performance.

\section{Measures}

Measures of positive affect, general and social self-efficacy, and conscientiousness were taken via self-reports using pen and paper methods. The supervisor ratings of performance were sent through mail.

Positive affect. Positive affect was measured using the positive and Negative affect Schedule (PANAS) developed by Watson, Clark and Tellegen (1988). This 20-item scale includes 10 items measuring positive affect and 10 items measuring negative affect. An example of a positive affect item is "Interested". Participants responded to the items on a 5-point Likert scale ranging from 1 (very slightly or not at all) to 5 (extremely). The total score for positive 
affect resulted from adding the scores on items $1,3,5,9,10,12,14,16,17$, and 19. Scores can range from 10 to 50 , and the higher scores represented higher levels of positive affect. Watson, Clark and Tellegen (1988) reported an alpha of .88 for positive affect. In this study, the Cronbach alpha for the PANAS scale was .85 .

General self-efficacy. General self-efficacy was measured with a 17-item GSE measure developed by Sherer, Maddux, Mercandante, Prentice-Dunn, Jacobs, and Rogers (1982). Participants were instructed to answer to the items on a 7-point Likert scale ranging from 1 (strongly disagree) to 7 (strongly agree). The scale consisted on 6 positively phrased items like "If I can't do the job the first time, I keep trying until I can", and 11 negatively phrased items like "I give up on things before completing them". Of the 17 items, 11 were reverse coded questions. The total scores resulted from adding the scores on all items, and the higher scores represented higher levels of self-efficacy. Past research reported an alpha of .86 for this measure of general self-efficacy (Sherer et al., 1982). In this study, the Cronbach alpha for the GSE scale was .82 .

Social self-efficacy. Social self-efficacy was measured with a 6-item subscale from a larger 40-item measure assessing behavioral self-efficacy developed based on contextual performance items found in Van Scotter, Motowidlo, and Cross (2000) and augmented by items created by subject matter experts at the Air Force Officer Training School. Participants were instructed to answer how effectively they could perform the items listed in that moment. Ratings were made on a 10-point Likert scale ranging from 0 (not very effectively) to 10 (extremely effectively). An example of a SSE item would be "cooperate with others in a team". The total scores resulted from adding the scores on all items, and the higher scores represented higher levels of social self-efficacy. Past research reported an alpha of . 72 for this measure of social 
self-efficacy (Barelka, Bobko, Dustin, Platt \& Van Scotter, YEAR). In this study, the Cronbach alpha for the SSE scale was .80 .

Conscientiousness. Conscientiousness was measured using a 5-item scale developed in the Air Force by Tupes and Christal (1961). This adjective scale asked respondents to rate their agreement on a 8-point scale (1-8) between two adjectives anchors and included two reverse coded items. However, as is often the case in these situations a strong reverse coded factor emerged (Magazine, Williams \& Williams, 1996), making it impossible to use the normal and reverse coded item sets in the same scale. To select one of these two sets to use, a reliability and exploratory factor analysis was completed which showed that the two reverse coded items had much stronger psychometric properties, so they were retained. Given that there were only two reverse coded items, the Cronbach's alpha was only .63 so a third item was added from the Openness to Experience scale (polish vs. clumsy, awkward) which is known to strongly relate to the conscientiousness scale (McCrae and Costa, 1987). The final three items have a Chronbach's Alpha of 0.70 .

Job Performance. Job performance was measured using a 38-item scale developed based on contextual performance items (Van Scotter, Motowidlo, \& Cross, 2000), and augmented by subject matter experts at the Air Force Officer Training School. Each item asked supervisors to rate the officers by comparing them to other officers in the unit. Responses were on a 7-point Likert scale $(1=$ Much below average, $7=$ Much above average $)$. An example item would be "delivering a briefing". In this study, the Cronbach alpha for this measure of performance was .97 . 


\section{CHAPTER III: RESULTS}

It was hypothesized that individuals with higher levels of positive affect would have higher levels of job performance. As reflected in Table 1, hypothesis 1 was not supported. Further, it was hypothesized that individuals with higher levels of general self-efficacy would have higher levels of job performance. As you can see in Table 1, hypothesis 2 was not supported either. It was also hypothesized that individuals with higher levels of social selfefficacy would have higher ratings of job performance. In Table 1, you can see that the findings supported hypothesis 3 .

Table 1

Correlations, Means, and Standard Deviations among Traits, Self-efficacy, and Job Performance

\begin{tabular}{llllll}
\hline Measure & 1 & 2 & 3 & 4 & 5 \\
\hline 1. Positive Affect & -- & & & \\
2. Conscientiousness & $.37 * * *$ & -- & & \\
3. General Self-efficacy & $.58 * * *$ & $.47 * * *$ & -- & \\
4. Social Self-efficacy & $.50 * * *$ & $.33 * * *$ & $.33 * * *$ & -- & \\
5. Job Performance & .14 & .17 & .16 & $.28 * *$ & - \\
& & & & \\
$M$ & & & & \\
SD & 4.13 & 6.41 & 5.58 & 8.59 & 5.53 \\
$-* \mathrm{p}<.05 ; * * \mathrm{p}<.01 ; * * * \mathrm{p}<.001$. & 0.51 & 1.04 & 0.69 & 0.95 & 1.00
\end{tabular}

Hypothesis 4 suggested that the relationship between positive affect and job performance would be mediated by general self-efficacy. As Figure 2 illustrates, the standardized regression coefficient between positive affect and general self-efficacy was statistically significant, but the standardized regression coefficient between general self-efficacy and job performance was not. The standardized indirect effect was $(.59)(.12)=.07$. We tested the significance of this indirect effect using bootstrapping procedures. Unstandardized indirect effects were computed for each of 5,000 bootstrapped samples, and the $95 \%$ confidence interval was computed by determining 
the indirect effects at the 2.5 th and 97.5 th percentiles. The bootstrapped unstandardized indirect effect was .47 , and the $95 \%$ confidence interval ranged from $-.54,1.54$. Thus, the indirect effect was not statistically significant. Hypothesis 4 was not supported.

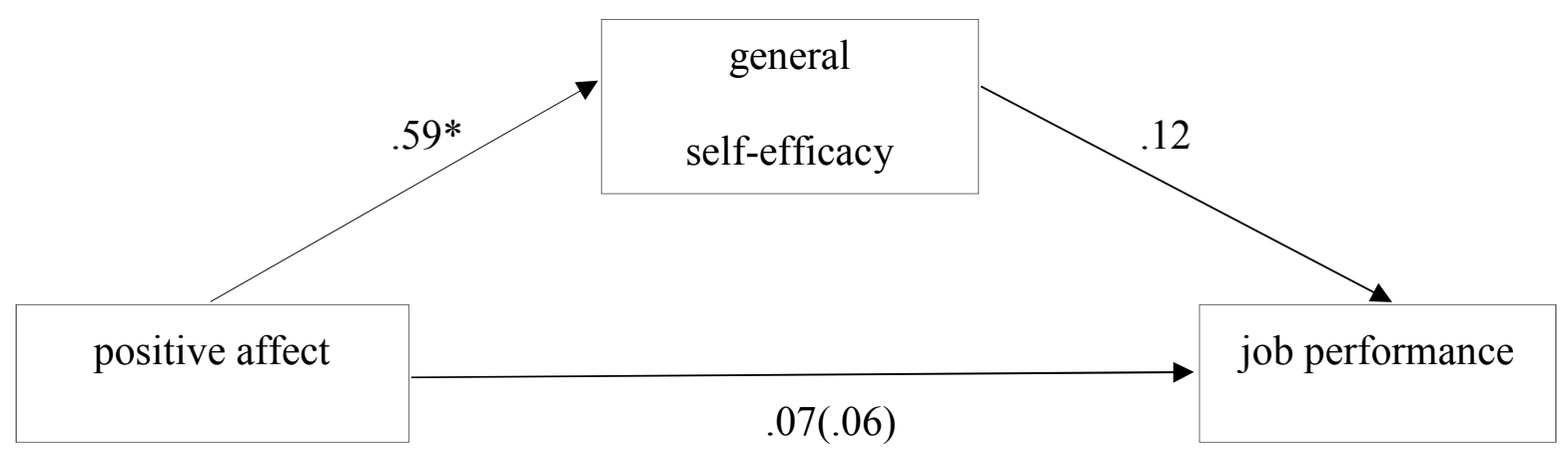

Figure 2. Standardized regression coefficients for the relation between positive affect and job performance as mediated by general self-efficacy. The standardized regression coefficient between positive affect and job performance, controlling for general self-efficacy, is in parentheses.

Hypothesis 5 suggested that the relationship between positive affect and job performance would be mediated by social self-efficacy. As Figure 3 illustrates, the standardized regression coefficient between positive affect and social self-efficacy was statistically significant, as was the standardized regression coefficient between social self-efficacy and job performance. The standardized indirect effect was $(.51)(.29)=.15$. We tested the significance of this indirect effect using bootstrapping procedures. Unstandardized indirect effects were computed for each of 5,000 bootstrapped samples, and the $95 \%$ confidence interval was computed by determining the indirect effects at the 2.5 th and 97.5 th percentiles. The bootstrapped unstandardized indirect effect was 1.10 , and the $95 \%$ confidence interval ranged from $.21,2.13$. Thus, the indirect effect was statistically significant. The evidence supported hypothesis 5 . 


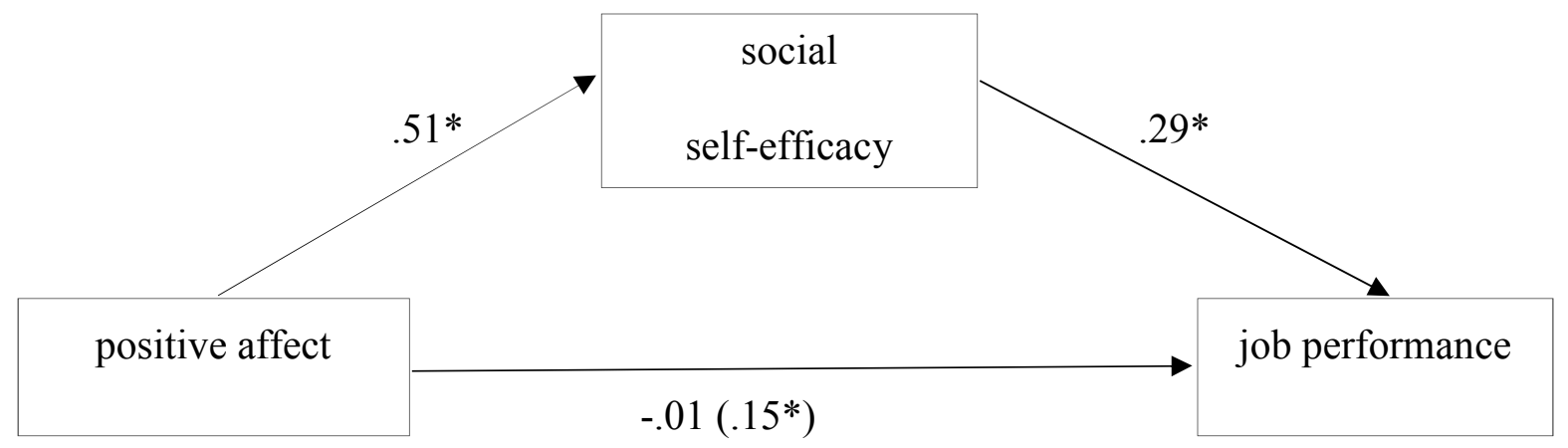

Figure 3. Standardized regression coefficients for the relation between positive affect and job performance as mediated by social self-efficacy. The standardized regression coefficient between positive affect and job performance, controlling for social self-efficacy, is in parentheses.

To test hypothesis 6 , conscientiousness was examined as a moderator of the relation between general self-efficacy and job performance. Conscientiousness and general self-efficacy were entered in the first step of the regression analysis. In the second step of the regression analysis, the interaction term between conscientiousness and general self-efficacy was entered, and it did not explain a significant increase in variance in job performance, $\Delta R^{2}=.04, F(3,116)$ $=1.52, p=.214$. Thus, not supporting hypothesis 6 , conscientiousness was not a significant moderator of the relationship between general self-efficacy and job performance. The unstandardized simple slope for participants $1 S D$ below the mean of conscientiousness was .38 , the unstandardized simple slope for participants with a mean level of conscientiousness was .39, and the unstandardized simple slope for participants $1 S D$ above the mean of conscientiousness was .40 .

Finally, to test hypothesis 7 , conscientiousness was examined as a moderator of the relation between social self-efficacy and job performance. Conscientiousness and social selfefficacy were entered in the first step of the regression analysis. In the second step of the 
regression analysis, the interaction term between conscientiousness and social self-efficacy was entered, and it explained a significant increase in variance in job performance, $\Delta R^{2}=.09, F(3$, $123)=4.11, p=.008$. Thus, supporting hypothesis 7 , conscientiousness was a significant moderator of the relationship between social self-efficacy and job performance. However, opposite of what was hypothesized, social self-efficacy was more predictive of job performance for those individuals high in conscientiousness. The unstandardized simple slope for participants $1 S D$ below the mean of conscientiousness was 1.29 , the unstandardized simple slope for participants with a mean level of conscientiousness was 1.73 , and the unstandardized simple slope for participants $1 S D$ above the mean of conscientiousness was 2.16 (see Figure 5).

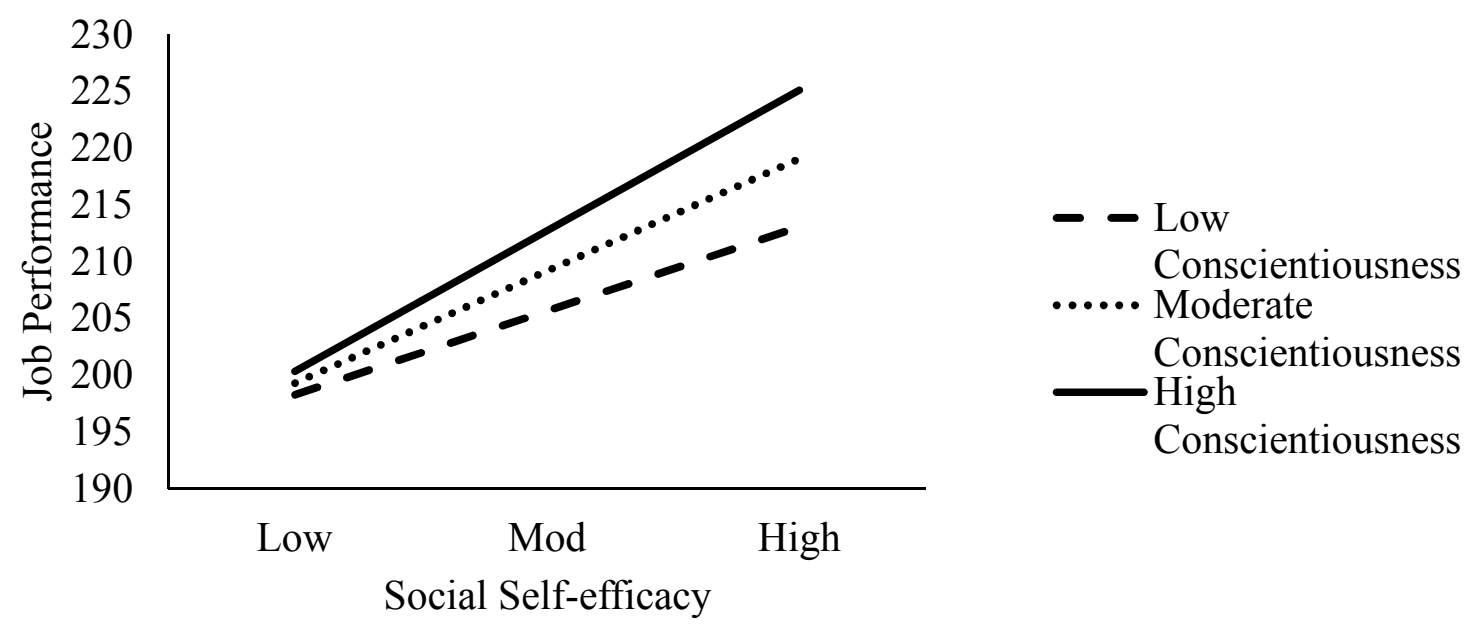

Figure 4. Simple slopes of social self-efficacy predicting job performance for 1 SD below the mean of conscientiousness, the mean of conscientiousness, and 1 SD above the mean of conscientiousness. 


\section{CHAPTER IV: DISCUSSION}

Several studies have found evidence linking trait positive affect and conscientiousness to job performance (Hurtz \& Donovan, 2000; Staw \& Barsade, 1993). Although a few studies have challenged the common notion that these traits do not change overtime, the variability of both traits during one's lifetime has been found to be rather small (Watson \& Walker, 1996; Rantanen et al., 2007). Their stable nature qualifies them as good predictors of performance for talent acquisition purposes. However, that same characteristic poses a limitation to interventions aiming at developing employees to achieve greater performance. The present study extends the previous research by examining two forms of self-efficacy (general and social) as mediators of the relation between positive affect and job performance. To determine if these mediators were especially predictive of job performance for those low in conscientiousness, trait conscientiousness was analyzed as a moderator of their relation with job performance. The study challenged previous findings and revealed several important findings concerning the role of social self-efficacy in the workplace.

\section{Traits and Job Performance}

Recent research indicates that conscientiousness is the second strongest predictor of performance and that higher levels of positive affect predicts higher levels of job performance. However, this study found no statistically significant relation between these traits and job performance over time in an Air Force officers sample. Isen and Means (1983) revealed that positive affect increased job performance by improving the decision-making process. Because our sample involved new officers, they may lack the necessary autonomy and decision-making opportunities in the military sector to replicate previous research showing that positive affect predicts job performance. Seo, Feldman and Bartunek (2004) revealed that individuals with high 
levels of positive affect were more likely to set higher goals and persist during goal pursuit. Novice officers' goals are likely to be set by their supervisors, therefore, although persistence of those goals should still be enhanced by positive affect, removing the process of setting their own goals, might also have contributed to the lack of significant association between positive affect and the officers' performance.

Furthermore, the PANAS measure administered at one point in time only, could have mistakenly assessed officers' state positive affect instead of trait positive affect. To accommodate measurement of trait or state affect, survey instructions are usually modified, so that participants are asked to recall trait affect in general, or at a specific time (Merz \& Roesch, 2011). The instructions in this study asked the officers to indicate to what extent they have felt this way during the past year. Although such tailored language should have been sensitive to capturing dispositional affect, measuring it at a single time-point generates doubt of whether that is the case. Diener and Emmons (1984) suggest that the best way to capture the variation of trait and state affect would be making multiple assessments of daily state affect and using the average of those scores to assess trait affect. Thus, although the PANAS measure administered was intended to capture trait affect, there is a possibility that the failure to find conclusive evidence that connects trait positive affect and job performance is due to a failure to assess trait affect.

Looking at the relation between conscientiousness and job performance, correlational analyses revealed no statistically significant association between the two for recently appointed Air Force officers. Taking a close look at Roberts et al.'s (2012) facets that form conscientiousness, including orderliness, industriousness, self-control, and responsibility, an observation must be made that could have contributed to the present findings. The Officer Training School (OTS) is a rigorous nine-week program that includes activities and rules that 
promote discipline, increasing those individuals' orderliness, industriousness, self-control, and responsibility (U.S. AIR FORCE). Perhaps, once these behaviors became general standards for the job as an air force officer, they began to perform them out of obligation. Thus, regardless of the officer's level of conscientiousness, every graduate at OTS may have displayed attitudes usually associated with highly conscientious employees.

\section{Self-efficacy as a Mediator of the Positive Affect-Job Performance Relation}

The finding that social self-efficacy is a mediator of the relation between positive affect and job performance is consistent with research that shows that positive affect is positively related to the amount and quality of social interactions (Berry \& Hansen, 1996), which in turn predicts higher job performance and higher salaries (Ferris, Witt, \& Hochwarter, 2001). On the other hand, general self-efficacy was not found to significantly mediate the relation between positive affect and job performance. Positive affect was positively associated with general selfefficacy, showing that positive affect does predict one's beliefs in the ability to perform in novel and social situations. However, neither positive affect nor general self-efficacy led to statistically significantly higher levels of job performance, thus not supporting the hypothesized the mediation model.

One possible explanation for the lack of significant association between general selfefficacy and achievement found in previous research (Chemers, 2001) is the performance criteria assessed in the present study. The performance measure used in this study was developed mostly to assess contextual performance, and measure task performance to a lesser degree. Following Motowidlo and Van Scotter's (1994) research on contextual and task performance in the U.S Air Force, a qualitative item analysis revealed that out of the 38 performance items, around 29 such as how effective is this officer at helping someone who needs it captured contextual performance, 
while around 9 items such as how effective is this officer at performing technical tasks captured task performance. Previous research suggest that task performance and contextual performance should be distinguished, building their argument that contextual performance captures helping, organizational citizenship, and prosocial behavior, and is best predicted by individual differences, including interpersonal skills (Motowidlo \& Van Scotter, 1994). Accordingly, social self-efficacy may predict performance when it is mostly contextual, and general self-efficacy or task-specific self-efficacy may be better predictors of task performance.

\section{Conscientiousness as a Moderator of the Self-efficacy-Job Performance Relation}

Conflicting with the direction of the hypothesized moderation effects that conscientiousness would have on the relation between self-efficacy and job performance, the results informed that social self-efficacy is more predictive of job performance for highly conscientious officers. The present study hypothesized the opposite moderating effect based on the argument that social and general self-efficacy could act as substitutes of conscientiousness, leading to similar desirable behavioral outcomes at work. However, the finding indicates that those highly conscientious and highly socially self-efficacious will achieve the greatest job performance. According to research like Erozkan's (2013), communication and interpersonal skills are important predictors of social self-efficacy. Therefore, the combination of communication and interpersonal skills with being organized and responsible may be the strongest predictor of job performance as inferred from this study. Conscientiousness was not

found to be a statistically significant moderator of the relation between general self-efficacy and job performance. It must be noted that neither general self-efficacy nor conscientiousness were found to be significantly predictive of job performance in this study. 


\section{Implications of Self-efficacy in the Workplace}

Considerable attention has been given to self-efficacy in the workplace. However, little research has proposed to develop employee self-efficacy to aid those individuals that lack advantageous traits such as positive affect. The findings indicate that social self-efficacy is a mediator in the relation between positive affect and job performance. Thus, given its malleability (Gist et al., 1989), employers could design interventions to increase social self-efficacy. This intervention would benefit from the extensive knowledge that Bandura's theory (1994) provides regarding sources of self-efficacy.

The most effective among the four main sources is mastery experience, which consists on building beliefs in self personal efficacy by experiencing successes and failures. Easy successes are easily discouraged by failure, but the hard ones that include some setbacks, often convince individuals that they have what it takes to succeed, even in the presence of adversity. The second source of self-efficacy is through vicarious experiences, in which one observes that similar people succeed putting effort, which raises the observer's beliefs that they also possess the capabilities to master complex activities. The third way of strengthening self-efficacy is through social persuasion, which occurs when people are persuaded verbally that they have the capabilities to master any given activity. The fourth way of altering one's beliefs of efficacy is to change the interpretation of the physical states and reduce stress reactions. People with high levels of self-efficacy are likely to perceive their arousal as an energizing enabler of performance, whereas people with low levels of self-efficacy regard their arousal as a weakening obstacle to performance (Bandura, 1994).

The intervention could include exercises that are connected to these sources. First, coordinators (supervisors?) could provide some sort of problem that employees must solve. To 
emerge stronger, this problem should be complex but attainable, and employees should be able to rebound from setbacks. Employees with similar responsibilities should be in pairs or groups. Ideally, someone with lower self-efficacy would get paired with someone with higher selfefficacy and the former would observe the latter complete a problem or task before completing his/hers. To increase the employees' belief that they are capable to successfully complete the task, supervisors should provide positive feedback while they are working on it. This feedback should reflect the employees' positive qualities and the supervisors' trust in the employees' ability to perform. To reduce stress among employees, mindfulness meditation, described in current clinical and research context as non-judgmental attention to experiences in the present moment (Tang, Hölzel, \& Posner, 2015), has shown to be an effective approach (Kabat-Zinn et al., 1992). The intervention could include some information and practice of mindfulness tools that can turn employees' stressful arousal into exciting arousal to excel.

It must be noted that employees' lack of positive affect will have an impact on their openness to such intervention. Consistent with Forgas' (2002) research, employees with low positive affect are expected to be less friendly, confident, relaxed, comfortable, active, interested and competent. Thus, they will be likely to have feelings of anxiety in a group training, to be less interested, and to be less friendly to coworkers. Extensive literature on affectivity may aid organizations and help employees overcome their negative judgements about the intervention. Studies like Totterdell et al.'s (1998) showed that people's moods are influenced by the collective mood of their co-workers over time. Creating a culture that encourages positive emotions towards training and development could improve the outlook of those employees who tend to not feel positively about interventions. Even if employees struggle to be influenced by their coworkers and culture, supervisor support has been shown to enhance employees' training 
efficacy, learning goal orientation, and their motivation to transfer (Chiaburu, Van Dam, \& Hutchins, 2010). It is recommended that supervisors establish a trusting relationship with their subordinates and encourage them to improve their skills. Research has also shown that performing acts of kindness reduces social avoidance goals (Trew \& Alden, 2015). Organizations may encourage employees to invest some of their time volunteering or contributing to some greater cause.

\section{Implications of Self-efficacy in Research}

The current findings indicate that compared to general self-efficacy (.16), social selfefficacy is a stronger predictor $\left(.28^{* *}\right)$ of job performance. Self-efficacy was meant to be measured as it relates to specific tasks (Gist, 1987), and as it has been shown in research on selfesteem and performance (Tharenou, 1979), predictive power might be sacrificed as the measure becomes more generalized. A meta-analysis about the influence of academic self-efficacy on academic performance found a significant relation $\left(.33^{* *}\right)$ between the two (Honicke \& Broadbent, 2016). In the mathematics domain, Hackett and Betz found a moderately strong positive relation between mathematics self-efficacy and mathematics performance $\left(.44^{* *}\right)$. These are two examples of the use of specific self-efficacies, and as we can observe, they produce higher coefficients with each domain-specific performance. Moreover, Honicke and Broadbent (2016) cited Bandura (1997) explaining that "the original context in which beliefs should be measured, is in situations no greater than at a domain-specific level", and further note that the interpretation of that within the context of research is inconsistent.

Bandura's recommendation for the use of domain-specific self-efficacy, the success seen in many studies when a specific self-efficacy has been compared to performance and the present study's findings, call for further research examining whether general self-efficacy should become 
obsolete and measures of specific self-efficacy should be developed for every domain.

Specifically, this study has shown the importance of social self-efficacy in the workplace, and further research is necessary to understand how to increase social self-efficacy in organizational contexts.

\section{Limitations and Further Research}

This study had several limitations. The sample was moderately small which could have contributed to the lack of significance of the predicting effects of positive affect and general selfefficacy on job performance. This study found a non-significant coefficient of .14 between positive affect and job performance with 131 participants but with a similar coefficient of .16, the meta-analysis by Kaplan, Bradley, Luchman and Haynes (2009) found that the relation was significant with a sample of 3084 individuals. The present study also found a non-significant coefficient of .16 between general self-efficacy and job performance with 131 participants but with a coefficient of .19, which is not much higher, the study by Pillai and Williams (2004) found that the relation was significant with a sample of 271 participants. Further research could use a larger sample to test the latter relations, the mediation of general self-efficacy between positive affect and job performance and the moderation effects of conscientiousness to the relation between general self-efficacy and job performance.

Also, the sample consisted of novice officers from the Air Force who had recently undergone the same training, thus taking some of the original between-person variability away. The military sector operates in a different manner compared to other sectors, which might explain the current findings on the predictive validity of positive affect and conscientiousness on job performance. Although the design of the present study with a sample formed by employees may be more generalizable than a study with a sample formed by non-employed individuals, the 
sector the participants work in may have decreased the external validity of the findings. This study also claimed predictive validity because job performance was assessed one to two years after personality traits were measured but to appropriately study a mediation, self-efficacy should have also been measured later than positive affect. A similar study design with a sample of employees from a different sector could yield different results. Ideally, positive affect and conscientiousness would be measured first, followed by general and social self-efficacy at a second point in time, and a measure of job performance a couple years later.

Moreover, the measure of job performance mostly included contextual performance and fewer items on task performance, which could explain how social self-efficacy resulted more relevant than general self-efficacy. A second study could be performed in which social selfefficacy predicts contextual performance and general or task-specific self-efficacy predicts task performance. Another limitation is the lack of power, which led to various analyses that could have been synthesized with a moderated mediation. A CFA analysis with 1 and 2 factors in the positive and negative affect scales would have also been interesting to add to this study. Although most researchers agree that positive and negative affect are not two ends of the same continuum, an analysis with the present sample would have clarified any readers' confusion.

\section{Conclusion}

This study has contributed to the literature by providing findings that indicate that social self-efficacy predicts future job performance in the Air Force. By proving mediating effects of social self-efficacy on the relation between positive affect and job performance, this study can confidently suggest employers to design interventions to increase employee social self-efficacy, especially for those low in positive affect. Further, previous literature combined with the results of this study raise the question of whether general self-efficacy should become obsolete because 
its generalizability might have reduced self-efficacy's predictive power. Given the moderate to strong predictability that specific self-efficacies have been found to have with domain-specific performance, more specific self-efficacy measures should be developed and validated.

Finally, besides the results presented in this study, the broader idea behind the present research calls for the search of malleable mediators that employers can rely on to design developmental opportunities for employees who are innately disadvantaged. 


\section{REFERENCES}

Abele, Andrea E. \& Spurk, Daniel. (2009). The longitudinal impact of self-efficacy and career goals on objective and subjective career success. Journal of Vocational Behavior 74, 1, 53-62. https://doi.org/10.1016/j.jvb.2008.10.005.

Ashby, F. G., Isen, A. M., \& Turken, A. U. (1999). A neuropsychological theory of positive affect and its influence on cognition. Psychological Review, 106(3), 529-550. https://doi.org/10.1037/0033-295X.106.3.529

Bandura, A., \& Wood, R. E. (1989). Effect of perceived controllability and performance standards on self-regulation of complex decision making. Journal of Personality and Social Psychology, 56, 805-814.

Baron, R.A. (1990), Environmentally Induced Positive Affect: Its Impact on Self $\square$ Efficacy, Task Performance, Negotiation, and Conflict1. Journal of Applied Social Psychology, 20: 368384. doi:10.1111/j.1559-1816. 1990.tb00417.x

Barrick, M. R., Mount, M. K., \& Strauss, J. P. (1993). Conscientiousness and performance of sales representatives: Test of the mediating effects of goal setting. Journal of Applied Psychology, 78(5), 715-722. https://doi.org/10.1037/0021-9010.78.5.715

Baumeister, R.F., Vohs, K.D. (2016). Chapter Two - Strength Model of Self-Regulation as Limited Resource: Assessment, Controversies. Advances in Experimental Social Psychology, Academic Press 54, 67-127. https://doi.org/10.1016/bs.aesp.2016.04.001.

Beck, James, W., Schmidt, Aaron M. (2012). Taken out of context? Cross-level effects of between-person self-efficacy and difficulty on the within-person relationship of selfefficacy with resource allocation and performance. Organizational Behavior and Human Decision Processes 119, 2, 195-208. https://doi.org/10.1016/j.obhdp.2012.06.009. 
Berry, D. S., \& Hansen, J. S. (1996). Positive affect, negative affect, and social interaction. Journal of Personality and Social Psychology, 71(4), 796-809. https://doi.org/10.1037/0022-3514.71.4.796

Brayfield, A. H., \& Crockett, W. H. (1955). Employee attitudes and employee performance. Psychological Bulletin, 52(5), 396-424. https://doi.org/10.1037/h0045899

Chemers, M. M., Hu, L.-t., \& Garcia, B. F. (2001). Academic self-efficacy and first year college student performance and adjustment. Journal of Educational Psychology, 93(1), 55-64. https://doi.org/10.1037/0022-0663.93.1.55

Chiaburu, D.S., Van Dam, K. and Hutchins, H.M. (2010), Social Support in the Workplace and Training Transfer: A longitudinal analysis. International Journal of Selection and Assessment, 18: 187-200. doi:10.1111/j.1468-2389.2010.00500.x

Connolly, J. (1989). Social self-efficacy in adolescence: Relations with self-concept, social adjustment, and mental health. Canadian Journal of Behavioural Science / Revue canadienne des sciences du comportement, 21(3), 258-269.

https://doi.org/10.1037/h0079809

Damen, F., Van Knippenberg, B. and Van Knippenberg, D. (2008). Affective Match in Leadership: Leader Emotional Displays, Follower Positive Affect, and Follower Performance1. Journal of Applied Social Psychology, 38: 868-902. doi:10.1111/j.15591816.2008.00330.x

Diener, E., \& Emmons, R. A. (1984). The independence of positive and negative affect. Journal of Personality and Social Psychology, 47(5), 1105-1117. https://doi.org/10.1037/00223514.47.5.1105 
Erozkan, A. (2013). The Effect of Communication Skills and Interpersonal Problem-Solving Skills on Social Self-Efficacy. Educational Sciences: Theory \& Practice 13(2) 739-745

Ferris, G. R., Witt, L. A., \& Hochwarter, W. A. (2001). Interaction of social skill and general mental ability on job performance and salary. Journal of Applied Psychology, 86(6), 1075-1082. https://doi.org/10.1037/0021-9010.86.6.1075

Forgas, J. P., Bower, G. H., \& Moylan, S. J. (1990). Praise or blame? Affective influences on attributions for achievement. Journal of Personality and Social Psychology, 59, 809-818

Gist, M. E., Schwoerer, C., \& Rosen, B. (1989). Effects of alternative training methods on selfefficacy and performance in computer software training. Journal of Applied Psychology, 74(6), 884-891. https://doi.org/10.1037/0021-9010.74.6.884

Gist, Marilyn E. and Mitchell, Terence R. (1992). Self-Efficacy: A Theoretical Analysis of Its Determinants and Malleability. AMR, 17, 183-211, https://doi.org/10.5465/amr.1992.4279530

Goldberg, L. R. (1993). The structure of phenotypic personality traits. American Psychologist, 48(1), 26-34. https://doi.org/10.1037/0003-066X.48.1.26

Hendricks, K. S. (2016). The Sources of Self-Efficacy: Educational Research and Implications for Music. Update: Applications of Research in Music Education, 35(1), 32-38. https://doi.org/10.1177/8755123315576535

Higgins, E. T., Shah, J., \& Friedman, R. (1997). Emotional responses to goal attainment: Strength of regulatory focus as moderator. Journal of Personality and Social Psychology, 72(3), 515-525. https://doi.org/10.1037/0022-3514.72.3.515Hoppock, R. (1935). Job satisfaction. Harper. 
Honicke, Toni, Broadbent, Jaclyn. (2016). The influence of academic self-efficacy on academic performance: A systematic review. Educational Research Review, 17, 63-84. https://doi.org/10.1016/j.edurev.2015.11.002.

Hurtz, G. M., \& Donovan, J. J. (2000). Personality and job performance: The Big Five revisited. Journal of Applied Psychology, 85(6), 869-879. https://doi.org/10.1037/00219010.85.6.869

Iaffaldano, M. T., \& Muchinsky, P. M. (1985). Job satisfaction and job performance: A metaanalysis. Psychological Bulletin, 97(2), 251-273. https://doi.org/10.1037/00332909.97.2.251

Isen, Alice M. \& Means, Barbara (1983). The Influence of Positive Affect on Decision-Making Strategy. Social Cognition 2(1), 18-31. https://doi.org/10.1521/soco.1983.2.1.18

Isen, A.M., Reeve, J. The Influence of Positive Affect on Intrinsic and Extrinsic Motivation: Facilitating Enjoyment of Play, Responsible Work Behavior, and Self-Control. Motiv Emot 29, 295-323 (2005). https://doi.org/10.1007/s11031-006-9019-8

Jensen-Campbell, Lauri A., Rosselli, Monica, Workman, Katie A., Santisi, Mirtha, Rios, Jasmin D., Bojan, Debbie. (2002). Agreeableness, conscientiousness, and effortful control processes. Journal of Research in Personality 36(5), 476-489. https://doi.org/10.1016/S0092-6566(02)00004-1.

Kampkuiper, J. (2015). The effect of positive and negative feedback on self- efficacy, cognitive trust and affective trust. 5th IBA Bachelor Thesis Conference, July 2nd, 2015, Enschede, The Netherlands.

Klein, Howard J. (1989): An Integrated Control Theory Model of Work Motivation. AMR, 14, 150-172, https://doi.org/10.5465/amr.1989.4282072 
Latham, G. P., \& Frayne, C. A. (1989). Self-management training for increasing job attendance: A follow-up and a replication. Journal of Applied Psychology, 74, 411-416.

Locke, E. A., \& Latham, G. P. (1990). A theory of goal setting \& task performance. PrenticeHall, Inc.

Locke, E. A., \& Latham, G. P. (2006). New Directions in Goal-Setting Theory. Current Directions in Psychological Science, 15(5), 265-268. https://doi.org/10.1111/j.14678721.2006.00449.x

Luszczynska, A., Gutiérrez $\square$ Doña, B. and Schwarzer, R. (2005), General self $\square$ efficacy in various domains of human functioning: Evidence from five countries. International Journal of Psychology, 40, 80-89. doi:10.1080/00207590444000041

Jensen-Campbell, L. A., \& Malcolm, K. T. (2007). The Importance of Conscientiousness in Adolescent Interpersonal Relationships. Personality and Social Psychology Bulletin, 33(3), 368-383. https://doi.org/10.1177/0146167206296104

Judge, T. A., Hulin, C. L., and Dalal, R. S. (2012). Job satisfaction and job affect. The Oxford Handbook of Industrial and Organizational Psychology, 496-525.

Judge, T. A., Thoresen, C. J., Bono, J. E., \& Patton, G. K. (2001). The job satisfaction-job performance relationship: A qualitative and quantitative review. Psychological Bulletin, 127(3), 376-407. https://doi.org/10.1037/0033-2909.127.3.376

Kabat-Zinn, J., Massion, A. O., Kristeller, J., Peterson, L. G.,Fletcher, K., Pbert, L. (1992). $\mathrm{E} \square$ ectiveness of a medi-tation-based stress reduction program in the treatment of anxiety disorders. American Journal of Psychiatry, 149, 936-943. 
MacCann, Carolyn, Duckworth, Angela Lee, Roberts, Richard D. (2009). Empirical identification of the major facets of Conscientiousness. Learning and Individual Differences 19(4), 451-458, https://doi.org/10.1016/j.lindif.2009.03.007.

Martin, Garry \& Pear, Joseph J. 2019. Behavior Modification: What It Is and How to Do It. Routledge, 11 edition.

Matsushima, R., \& Shiomi, K. (2003). Developing a Scale of Self-Efficacy in Personal Relationships for Adolescents. Psychological Reports, 92(1), 177-184. https://doi.org/10.2466/pr0.2003.92.1.177

Merz, Erin L., Roesch, Scott C. (2011). Modeling trait and state variation using multilevel factor analysis with PANAS daily diary data. Journal of Research in Personality 45(1), 2-9, https://doi.org/10.1016/j.jrp.2010.11.003.

Mount, M. K., Barrick, M. R., \& Strauss, J. P. (1999). The Joint Relationship of Conscientiousness and Ability with Performance: Test of the Interaction Hypothesis. Journal of Management, 25(5), 707-721. https://doi.org/10.1177/014920639902500505

Norma Romero, Alicia, Fernández-Berrocal, Pablo, Salazar-Estrada, José Guadalupe, GallegosGuajardo, Julia. (2017). Positive emotions, self-esteem, interpersonal relationships and social support as mediators between emotional intelligence and life satisfaction. Journal of Behavior, Health \& Social Issues 9(1), 1-6. https://doi.org/10.1016/j.jbhsi.2017.08.001.

Nutt, P.C. (2002), Why Decisions Fail: Avoiding the Blunders and Traps that Lead to Debacles, Berrett-Koehler, Williston, VT. 
Pavot, William, Diener, Ed, Colvin, C. Randall \& Sandvik, Ed (1991). Further Validation of the Satisfaction with Life Scale: Evidence for the Cross-Method Convergence of Well-Being Measures. Journal of Personality Assessment, 57(1), 149-161, DOI: 10.1207/s15327752jpa5701_17

Pillai, R. and Williams, E.A. (2004). Transformational leadership, self $\square$ efficacy, group cohesiveness, commitment, and performance. Journal of Organizational Change Management, 17, 144-159. https://doi.org/10.1108/09534810410530584

Ralston, Shane J. Doing versus Thinking: John Dewey's Forgotten Critique of Scientific Management. Southwest Philosophy Review, Volume 30, January 2014. DOI: https://doi.org/10.5840/swphilreview201430120

Rantanen, J., Metsapelto, R. $\square$ L., Feldt, T., Pulkinnen, L. and Kokko, K. (2007), Long $\square$ term stability in the Big Five personality traits in adulthood. Scandinavian Journal of Psychology, 48, 511-518. doi:10.1111/j.1467-9450.2007. 00609.x

Reeshad, S.D. and B. Bolunmez, (2016). Evidence-based strategies to improve workplace decisions: Small steps, big effects. SHRM-SIOP Science of HR Series. George Mason University.

Roberts, B. W., Lejuez, C., Krueger, R. F., Richards, J. M., \& Hill, P. L. (2014). What is conscientiousness and how can it be assessed? Developmental Psychology, 50(5), 13151330. https://doi.org/10.1037/a0031109

Roberts, B. W., Walton, K. E., \& Viechtbauer, W. (2006). Patterns of mean-level change in personality traits across the life course: A meta-analysis of longitudinal studies. 
Silver, W. S., Mitchell, T. R. \& Gist, M. E. (1991). "Interpreting performance information: The influence of self-efficacy on causal attributions for successful and unsuccessful performance." Unpublished manuscript, University of Washington, Seattle.

Stajkovic, A. D., \& Luthans, F. (1998). Self-efficacy and work-related performance: A metaanalysis. Psychological Bulletin, 124(2), 240-261. https://doi.org/10.1037/00332909.124.2.240

Sun, Shuhua , Chen, Huaizhong \& Song, Zhaoli. (2016). Cross-level moderating effects of Conscientiousness on within-person relationships of self-efficacy to effort allocation. Human Performance, 29(5), 447-459, DOI: 10.1080/08959285.2016.1245733

Schunk, Dale H. (1990) Goal Setting and Self-Efficacy During Self-Regulated Learning. Educational Psychologist, 25(1), 71-86, DOI: 10.1207/s15326985ep2501_6

Seo, Myeong-Gu, Barrett, Lisa F. \& Bartunek, Jean M. (2004). The Role of Affective Experience in Work Motivation. $A M R, 29,423-439$, https://doi.org/10.5465/amr.2004.13670972

Sherer, M., Maddux, J. E., Mercandante, B., Prentice-Dunn, S., Jacobs, B., \& Rogers, R. W. (1982). The Self-Efficacy Scale: Construction and Validation. Psychological Reports, 51(2), 663-671. https://doi.org/10.2466/pr0.1982.51.2.663

Specht, J., Egloff, B., \& Schmukle, S. C. (2011). Stability and change of personality across the life course: The impact of age and major life events on mean-level and rank-order stability of the Big Five. Journal of Personality and Social Psychology, 101(4), 862-882. https://doi.org/10.1037/a0024950 
Staw, B., \& Barsade, S. (1993). Affect and Managerial Performance: A Test of the Sadder-butWiser vs. Happier-and-Smarter Hypotheses. Administrative Science Quarterly, 38(2), 304-331. doi:10.2307/2393415

Tang, Y., Hölzel, B. \& Posner, M. (2015). The neuroscience of mindfulness meditation. Nat Rev Neurosci 16, 213-225. https://doi.org/10.1038/nrn3916

Taylor, Frederick W. The Principles of Scientific Management. New York NY: Harper \& Bros, 1911.

Tharenou, Phyllis. (1979). Employee self-esteem: A review of the literature. Journal of Vocational Behavior, 15, 316-346. https://doi.org/10.1016/0001-8791(79)90028-9.

Totterdell, P., Kellett, S., Teuchmann, K., \& Briner, R. B. (1998). Evidence of mood linkage in work groups. Journal of Personality and Social Psychology, 74(6), 1504-1515. https://doi.org/10.1037/0022-3514.74.6.1504

Trew, J.L., Alden, L.E. (2015). Kindness reduces avoidance goals in socially anxious individuals. Motiv Emot 39, 892-907. https://doi.org/10.1007/s11031-015-9499-5

Vaidya, J.G., Gray, E.K., Haig, J.R., Mroczek, D.K. and Watson, D. (2008), Differential Stability and Individual Growth Trajectories of Big Five and Affective Traits During Young Adulthood. Journal of Personality, 76: 267-304. doi:10.1111/j.1467-6494.2007. 00486.x

Vancouver, J. B., Thompson, C. M., Tischner, E. C., \& Putka, D. J. (2002). Two studies examining the negative effect of self-efficacy on performance. Journal of Applied Psychology, 87(3), 506-516. https://doi.org/10.1037/0021-9010.87.3.506 
Van Scotter, J. R., \& Motowidlo, S. J. (1996). Interpersonal facilitation and job dedication as separate facets of contextual performance. Journal of Applied Psychology, 81(5), 525531. https://doi.org/10.1037/0021-9010.81.5.525

Watson, D., \& Clark, L. A. (1984). Negative affectivity: The disposition to experience aversive emotional states. Psychological Bulletin, 96(3), 465-490. https://doi.org/10.1037/00332909.96.3.465

Watson, D., \& Walker, L. M. (1996). The long-term stability and predictive validity of trait measures of affect. Journal of Personality and Social Psychology, 70(3), 567-577. https://doi.org/10.1037/0022-3514.70.3.567

Winslow, C. J., Hu, X., Kaplan, S. A., \& Li, Y. (2017). Accentuate the positive: Which discrete positive emotions predict which work outcomes? The Psychologist-Manager Journal, 20(2), 74-89. https://doi.org/10.1037/mgr0000053

Yeo, G. B., \& Neal, A. (2006). An examination of the dynamic relationship between selfefficacy and performance across levels of analysis and levels of specificity. Journal of Applied Psychology, 91(5), 1088-1101. https://doi.org/10.1037/0021-9010.91.5.1088 